\title{
Cervicovaginal cytokines, sialidase activity and bacterial load in reproductive-aged women with intermediate vaginal flora
}

\author{
Mariana Morena de Vieira Santos-Greatti ${ }^{a}$, Márcia Guimarães da Silva ${ }^{a}$, \\ Carolina Sanitá Tafner Ferreira ${ }^{\mathrm{a}}$, Camila Marconi ${ }^{\mathrm{a}, \mathrm{b}, *}$ \\ a Department of Pathology, Botucatu Medical School, UNESP - Univ. Estadual Paulista, Botucatu, São Paulo, Brazil \\ ${ }^{b}$ Department of Basic Pathology - Federal University of Paraná, Curitiba, Paraná, Brazil
}

\section{A R T I C L E I N F O}

\section{Article history:}

Received 2 June 2016

Received in revised form 8 August 2016

Accepted 15 August 2016

\section{Keywords:}

Intermediate flora

Bacterial vaginosis

Cytokine

Sialidases

Gardnerella vaginalis

\begin{abstract}
A B S T R A C T
Studies have shown that not only bacterial vaginosis, but also intermediate vaginal flora has deleterious effects for women's reproductive health. However, literature still lacks information about microbiological and immunological aspects of intermediate flora. Objective: To characterize intermediate flora regarding levels of Interleukin (IL)-1beta, IL-6, IL-8, tumor necrosis factor-alpha, interleukin 1 receptor antagonist (IL-1 ra), IL-10, sialidase; loads of Gardnerella vaginalis, total bacteria and to verify whether it is closer related to normal flora or bacterial vaginosis. This cross-sectional study enrolled 526 non-pregnant reproductive-aged women distributed in 3 groups according to pattern of vaginal flora using Nugent's system in normal, intermediate and bacterial vaginosis. Cervicovaginal levels of cytokines, sialidases, loads of $G$. vaginalis and total bacteria were assessed by ELISA, conversion of MUAN and quantitative real-time PCR, respectively. A principal component analysis(PCA) using all measured parameters was performed to compare the three different types of flora. Results showed that intermediate flora is associated with increased cervicovaginal IL-1beta in relation to normal flora( $\mathrm{P}<0.0001)$. When compared to bacterial vaginosis, intermediate flora has higher IL-8 and IL-10 levels $(\mathrm{P}<0.01)$. Sialidases were in significantly lower levels in normal and intermediate flora than bacterial vaginosis $(\mathrm{P}<0.0001)$. Loads of $G$. vaginalis and total bacterial differed among all groups $(\mathrm{P}<0.0001)$, being highest in bacterial vaginosis. PCA showed that normal and intermediate flora were closely scattered, while bacterial vaginosis were grouped separately. Conclusion: Although intermediate flora shows some differences in cytokines, sialidases and bacterial loads in relation to normal flora and bacterial vaginosis, when taken together, general microbiological and immunological pattern pattern of intermediate flora resembles the normal flora.
\end{abstract}

(C) 2016 Elsevier Ireland Ltd. All rights reserved.

\section{Introduction}

Normally, Lactobacillus species are the most frequent components of the vaginal microbiota (Ravel et al., 2011; Sobel, 2000). Maintenance of a healthy vaginal flora is crucial for protecting women against several sexually transmitted infections (STI), such as those caused by Chlamydia trachomatis, Neisseria gonorrhoeae, Trichomonas vaginalis and human immunodeficiency virus (HIV) (Brotman et al., 2012; Martin et al., 1999; Sewankambo et al., 1997; Weiesenfeld et al., 2003). The most common type of abnormal

\footnotetext{
* Corresponding author at: Department of Basic Pathology, Federal University of Paraná, UFPR - Curitiba, Paraná 81530-900, Brazil.

E-mail addresses: mariana_morena@hotmail.com (M.M.d.V. Santos-Greatti), mgsilva@fmb.unesp.br (M.G. da Silva), catafner@hotmail.com (C.S.T. Ferreira), marconi.cml@gmail.com, marconi@ufpr.br (C. Marconi).
}

vaginal flora is a polymicrobial entity called bacterial vaginosis in which the lactobacilli-dominated flora is replaced by an overgrowth of anaerobic bacteria (Spiegel et al., 1980). Mechanisms by which bacterial vaginosis increases the risk for STI acquisition and transmission remain poorly understood (Schwebke, 2001; Sturm-Ramirez et al., 2000), but it was already shown that the high levels of proinflammatory cytokines and bacterial sialidases found in this condition contributes for increasing the local vulnerability for infections (Cauci et al., 2003a; Cherpes et al., 2003). In fact, vaginal non-lactobacilli load of bacteria is positively correlated with higher levels of interleukin (IL)- 1 beta and several strains of the bacterial vaginosis-associated Gardnerella vaginalis are recognized as good sialidases-producers (Marconi et al., 2013a; Santiago et al., 2011).

Bacterial vaginosis can be detected in about $30 \%$ of reproductive aged women, but only half of them report symptoms such as increased vaginal discharge and unpleasant vaginal odor (Amsel 
et al., 1983; Klebanoff et al., 2004). The high rates of asymptomatic women with bacterial vaginosis challenges its diagnosis, leaving an expressive rate of the population in risk for STI acquisition. Currently, the gold standard for bacterial vaginosis diagnosis is the Nugent's scoring system, which is based in the microscopic semiquantification of bacterial morphotypes found in Gram-stained vaginal smears (Nugent et al., 1991). Using this method, vaginal flora can be classified as normal (scores 0-3), intermediate (scores 4-6) and bacterial vaginosis (scores 7-10). Although this is considered a good tool for bacterial vaginosis detection, the clinical meaning and importance of intermediate flora for women's reproductive health remains a matter of discussion. Intermediate flora is found in $19.2 \%$ to $30.0 \%$ of the population and is even less symptomatic than bacterial vaginosis (Cauci et al., 2002a; Guédou et al., 2014). Some studies showed that intermediate flora shares several of bacterial vaginosis risk factors and, more importantly, it is also associated with vulnerability for HIV (Guédou et al., 2012). However, little is known about the local microbiological and immunological aspects of women with intermediate flora and literature data have been controversial whether it should be considered as a transitory type of flora between normal and bacterial vaginosis or a single different entity (Donders, 2007; Srinivasan et al., 2010).

Considering the increasing evidences from the literature around the deleterious effect of intermediate flora for women's health and the few information available regarding the cytokine and sialidase profile of this condition, the aim of this study was to determine the cytokine levels of IL-1beta, IL-1ra, IL-6, IL-8, IL-10 and Tumor Necrosis Factor (TNF)-alpha, as well as sialidase activity, G. vaginalis and total bacterial load in intermediate flora. We also aimed to verify whether its overall profile is comparable to normal flora or bacterial vaginosis.

\section{Material and methods}

From 2010-2013, 783 non pregnant reproductive-aged women attending in one unit of Primary Health Care in Botucatu for routine cervical cancer screening were invited to participate of this cross-sectional study. Women were not eligible if they were menstruating, reported urinary loss, used antibiotics (30 days), had sexual intercourse $(48 \mathrm{~h})$, presented vaginal candidosis or cytolytic vaginosis, as well as those who tested positive for $C$. trachomatis and/or N. gonorrhoeae endocervicitis. All subjects were informed about the study aims and signed a consent form. This study was approved by the Ethics Committee Board of Botucatu Medical School, São Paulo State University (Protocol \#3629-2010). Sociodemographic and behavioral data were acquired by applying a standardized questionnaire.

During the physical exam for routine pap-smear screening, additional vaginal samples were taken to assess the local $\mathrm{pH}, 10 \% \mathrm{KOH}$ testing and to detect, by microscopy, the presence of Candida sp. pseudo hyphae, Trichomonas vaginalis and for classifying the vaginal flora according to the Nugent's scoring system in normal (scores 0-3), intermediate (4-6) and bacterial vaginosis (7-10) (Nugent et al., 1991). Endocervical samples were also taken for assessing of C. trachomatis and N. gonorrhoeae status by PCR, according to methods previously described (Ho et al., 1992; Marconi et al., 2012). Additionally, cervicovaginal lavages were performed using $3 \mathrm{~mL}$ of a sterile $0.9 \% \mathrm{NaCl}$ solution and, after allowing contact of the solution with the vaginal wall, samples were recovered using a plastic pipette. Cervicovaginal lavages samples were centrifuged at $800 \mathrm{xg}$ for $10 \mathrm{~min}$ within $4 \mathrm{~h}$ after collection, with pellets and supernatants stored separately at $-80^{\circ} \mathrm{C}$ until analysis. We excluded of this study those women whose vaginal smears were not satisfactory for analysis $(n=24)$ and those with blood in the cervicovaginal samples $(\mathrm{n}=11)$.
A total of 179 (22.9\%) women were tested positive for chlamydial endocervicitis, 14 (1.8\%) for gonorrhea and $2(0.3 \%)$ for both infections and therefore were excluded of this study, as well as those who presented vaginal vulvovaginal candidiasis $(n=25$, $3.2 \%$ ) and cytolytic vaginosis $(n=2,0.3 \%$ ). Therefore, among the 526 women considered eligible for this study, bacterial vaginosis was detected in 145 (27.6\%), while 63 (12.0\%) had intermediate flora and 318 (60.5\%) had lactobacilli-dominated vaginal flora. All pellets and supernatant samples from cervicovaginal lavages from women with bacterial vaginosis $(n=145,27.6 \%)$, intermediate flora $(n=63$, $12.0 \%$ ) and 145 (27.6\%) out of 318 randomly selected women with normal flora were subjected to determination of bacterial load and cytokine and sialidases quantification.

Bacterial DNA was extracted from the pellets of $1 \mathrm{~mL}$ of cervicovaginal samples using DNEasy Blood \&Tissue Kit (Qiagen, Valencia, CA) with final elution in $100 \mu \mathrm{L}$. Loads in number of copies $/ \mathrm{mL}$ of cervicovaginal samples of $G$. vaginalis and the conserved sequence of $16 \mathrm{~S}$ rRNA were determined by quantitative real-time PCR, using previously described primers (Smits et al., 2004; Zariffard et al., 2002). Reactions were performed individually in a final volume of $13 \mu \mathrm{L}$ using Maxima SYBR Green/ROX (Fermentas, St. Leon-Rot, Germany) in a LineGeneK equipment (Bioer, China), according to methods described elsewhere (Marconi et al., 2013a).

Interleukin-1beta, IL1-ra, IL-6, IL-8, IL-10 and TNF-alpha levels were measured in the supernatants by ELISA using Duo Set Kits (R\&D Systems, Minneapolis, MN) of cervicovaginal lavages, according to manufacturer's instructions. All samples were tested in duplicate and those with values set above the standard curve range were diluted ( $1: 5$ and $1: 10)$ and retested. The minimum detectable levels in the IL-1beta, IL-1ra IL-6, IL-8 and TNF-alpha assays were, respectively, $0.1 \mathrm{pg} / \mathrm{mL}, 775.0 \mathrm{ng} / \mathrm{mL}, 1.3 \mathrm{pg} / \mathrm{mL}, 7.8 \mathrm{pg} / \mathrm{mL}$, $0.4 \mathrm{pg} / \mathrm{mL}$. Intra and inter-assay variability remained $<10.0 \%$ for all cytokines.

Measurement of sialidase activity in the supernatants was performed using the fluorogenic substrate 2-(4-methylumbelliferyl)$\alpha-\mathrm{D}-\mathrm{N}$-acetylneuraminic acid (MUAN; Sigma-Aldrich, St. Louis, MO), according to protocol previously described (Marconi et al., 2013a,b). Comparison of discrete and continuous quantitative variables among the women with normal vaginal flora, intermediate and bacterial vaginosis was performed, respectively, by Chi-squared and non-parametric Kruskal Wallis test, followed by Dunn's multiple comparison post-test, when group effects were significant. Bacterial load, cytokine and sialidase levels among the groups were also compared with Kruskal-Wallis, followed by Dunn's test. Analyses were performed using GraphPad Prism 5.0 software (GraphPad, San Diego, CA) and $P<0.05$ was considered as significant. Principal component analysis (PCA) is a tool by which complex data are converted in simple values (principal components), allowing the evaluation of the samples based on the different variables that they express. We performed this analysis to compare the general profile of normal flora, intermediate and bacterial vaginosis samples based on the combination of their cytokine levels, sialidase activity, loads of G. vaginalis and total bacterial loads. An auto-scaled PCA analysis was performed with $\log _{10}$ transformed data using MVSP software, version 3.13a (Kovach Computing Services, Pentraeth, UK). Post-hoc analysis showed a power test superior to 95\%, considering the difference of IL-1beta among the groups with normal, intermediate flora and bacterial vaginosis.

\section{Results}

Sociodemographic, behavioral and gynecologic characteristics of the women enrolled are shown in Table 1, distributed according their pattern of vaginal flora. The three study groups did not 
Table 1

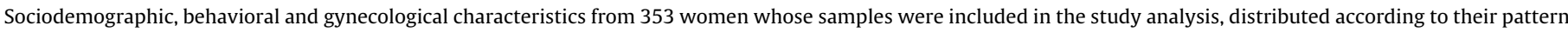
of vaginal flora.

\begin{tabular}{|c|c|c|c|c|}
\hline Variables ${ }^{*}$ & Normal flora $(\mathrm{n}=145)$ & Intermediate flora $(n=63)$ & Bacterial vaginosis $(n=145)$ & $P$ \\
\hline Age, median (range), years ${ }^{£}$ & $32[15-56]^{\mathrm{a}}$ & $33[18-54]^{\mathrm{a}}$ & $31[14-55]^{\mathrm{a}}$ & 0.23 \\
\hline \multicolumn{5}{|l|}{ Race (self-defined), n/total (\%) } \\
\hline White & $73 / 106(68.9)^{\mathrm{a}}$ & $39 / 49(79.6)^{a}$ & $79 / 125(63.2)^{\mathrm{a}}$ & 0.11 \\
\hline Nonwhite & $33 / 106(31.1)^{a}$ & $10 / 49(20.4)^{\mathrm{a}}$ & $46 / 125(36.8)^{a}$ & \\
\hline \multicolumn{5}{|l|}{ Marital status, $\mathrm{n} /$ total (\%) } \\
\hline Single & $23 / 125(18.4)^{b}$ & $10 / 56(17.9)^{\mathrm{b}}$ & $52 / 139(37.4)^{\mathrm{a}}$ & $<0.001$ \\
\hline Married & $102 / 125(81.6)^{\mathrm{a}}$ & $46 / 56(82.1)^{a}$ & $87 / 139(62.6)^{b}$ & \\
\hline Years at school, median (range) $)^{£}$ & $9[0,18]^{a}$ & $8[0,16]^{\mathrm{a}}$ & $9[0,28]^{\mathrm{a}}$ & 0.74 \\
\hline Remunerated activity, $\mathrm{n} /$ total $(\%)^{£}$ & $72 / 126(57.1)^{a}$ & $24 / 53(45.3)^{\mathrm{a}}$ & $78 / 138(56.5)^{\mathrm{a}}$ & 0.30 \\
\hline Smoking habit, $\mathrm{n} /$ total (\%) & $20 / 128(15.6)^{b}$ & $7 / 54(13.0)^{\mathrm{b}}$ & $38 / 138(27.5)^{\mathrm{a}}$ & 0.02 \\
\hline \multicolumn{5}{|l|}{ Sex partners, prior 12 months, n/total (\%) } \\
\hline 0 or 1 & $117 / 125(93.6)^{\mathrm{a}}$ & $47 / 53(88.7)^{\mathrm{a}}$ & $124 / 139(89.2)^{\mathrm{a}}$ & 0.39 \\
\hline 2 or more & $8 / 125(6.4)^{\mathrm{a}}$ & $6 / 53(11.3)^{a}$ & $15 / 139(10.8)^{\mathrm{a}}$ & \\
\hline Number of vaginal intercourse/week, median (range) $)^{£}$ & $3[0-7]^{\mathrm{a}}$ & $3[0-7]^{\mathrm{a}}$ & $2[0-30]^{\mathrm{a}}$ & 0.14 \\
\hline Previous $\mathrm{BV}^{\mathbb{}}, \mathrm{n}(\%)$ & $21 / 117(18.0)^{b}$ & $12 / 46(26.1)^{\mathrm{ab}}$ & $50 / 123(40.7)^{\mathrm{a}}$ & $<0.001$ \\
\hline Previous STD ${ }^{\uparrow}, \mathrm{n}(\%) \int$ & $19 / 114(16.7)^{\mathrm{a}}$ & $6 / 47(12.8)^{\mathrm{a}}$ & $9 / 123(7.3)^{\mathrm{a}}$ & 0.08 \\
\hline Consistent condom use, $\mathrm{n}(\%)$ & $10 / 79(12.7)^{\mathrm{a}}$ & $8 / 40(20.0)^{\mathrm{a}}$ & $18 / 130(13.4)^{\mathrm{a}}$ & 0.54 \\
\hline Hormonal contraception use, prior 12 months, n/total (\%) & $34 / 98(34.7)^{\mathrm{a}}$ & $11 / 45(24.4)^{\mathrm{a}}$ & $32 / 126(25.4)^{\mathrm{a}}$ & 0.27 \\
\hline \multicolumn{5}{|l|}{ Parity, n/total (\%) $\int$} \\
\hline 0 & $44 / 127(34.7)^{\mathrm{a}}$ & $17 / 53(32.1)^{\mathrm{a}}$ & $43 / 138(30.4)^{\mathrm{a}}$ & 0.83 \\
\hline$\geq 1$ & $83 / 127(65.4)^{\mathrm{a}}$ & $36 / 53(67.9)^{\mathrm{a}}$ & $95 / 138(68.8)^{a}$ & \\
\hline Vaginal $\mathrm{pH}$, median (range $)^{£}$ & $4.4(3.5,6.5)^{\mathrm{c}}$ & $4.5(4.0,6.5)^{\mathrm{b}}$ & $5.0(3.5,7.0)^{\mathrm{a}}$ & $<0.001$ \\
\hline \multicolumn{5}{|l|}{$\mathrm{KOH}$ test, n/total (\%) $\int$} \\
\hline Positive or doubtful & $17 / 123(13.8)^{c}$ & $16 / 55(29.1)^{b}$ & $87 / 133(65.4)^{\mathrm{a}}$ & $<0.001$ \\
\hline Negative & $106 / 123(86.2)^{\mathrm{a}}$ & $39 / 55(70.9)^{b}$ & $46 / 133(34.6)^{c}$ & \\
\hline
\end{tabular}

** Values followed by the same letter (a,b,c) did not differ statistically.

* Total of women may vary among the categories, as some of the data were unavailable or due to patients refusal to answer.

¿ BV: bacterial vaginosis.

ฯ STD: sexually transmitted diseases.

£ Kruskal-Wallis test, followed by the Dunn's multiple comparisons; $\mathrm{P}<0.05$.

$\int$

Chi-squared test; $\mathrm{P}<0.05$.

differ for major of the variables evaluated, but women who were single at enrollment $(\mathrm{p}<0.001)$, with smoking habit $(\mathrm{P}=0.02)$ and that reported at least one previous episode of bacterial vaginosis $(\mathrm{P}<0.001)$ were more frequent in bacterial vaginosis group. Regarding the clinical findings at time of enrollment, vaginal $\mathrm{pH}$ differed among all groups $(\mathrm{P}<0.001)$, with highest values in bacterial vaginosis, followed by intermediate and normal flora. The number of samples with positive or doubtful result at $10 \% \mathrm{KOH}$ test was also more frequent in women with bacterial vaginosis and intermediate flora when compared to normal $(\mathrm{P}<0.001)$.

Results of the comparison of the cytokines levels in the cervicovaginal samples among the three groups showed that for IL-1beta, levels were significantly higher in women with bacterial vaginosis $(56.0 \mathrm{pg} / \mathrm{mL}, 0.0-1950.0)$ and intermediate flora (28.7 pg/mL, 0.0-462.4) than in normal flora (7.8 pg/mL, 0.0-286.2) (Table 2). IL-1ra levels were significantly increased in bacterial vaginosis $(935.6 \mathrm{pg} / \mathrm{mL}, 775.4-8067.0)$ when compared to normal flora $(668.5 \mathrm{pg} / \mathrm{mL}, 70.4-4185.0)$, but not in relation to intermediate flora (1008.0 pg/mL, 0.0-3727.0). When evaluating IL-6 levels, this mediator did not differ between the groups, while IL- 8 was significantly higher in intermediate flora $(441.5 \mathrm{pg} / \mathrm{mL}, 0.0-2053.0)$, when compared to bacterial vaginosis $(260.9 \mathrm{pg} / \mathrm{mL}, 0.0-2220.0)$, but did not differ from women with normal vaginal flora $(294.3 \mathrm{pg} / \mathrm{mL}$, 0.0-2010.0). Women with intermediate flora also had significantly increased IL-10 (36.7 pg/mL, 0.0-417.1) when compared with bacterial vaginosis $(0.0 \mathrm{pg} / \mathrm{mL}, 0.0-62.3)$, but not in relation to normal flora $(0.0 \mathrm{pg} / \mathrm{mL}, 0.0-508.2)$. In fact, bacterial vaginosis had significantly lower IL-10 levels even when compared to normal flora. Levels of TNF-alpha did not differ among the groups.

Sialidase activity was detected in $83(57.2 \%)$ samples from women with bacterial vaginosis, while only in $8(12.7 \%)$ women with intermediate flora and 4 (2.8\%) with normal flora. Levels of sialidase measured in the cervicovaginal samples from women with bacterial vaginosis $(4.6 \mathrm{ng} / \mathrm{mL}, 0.0-576.4)$ were superior to those from intermediate $(0.0 \mathrm{ng} / \mathrm{mL}, 0.0-0.04)$ and normal flora (0.0 ng/mL, 0.0-5.2), $(\mathrm{P}<0.001)$, while intermediate flora had statistically the same sialidase levels than normal flora (Table 2). Results on the analyses of the quantitative PCR for G. vaginalis and the conserved sequence of 16S rRNA, to assess the total bacterial load, showed statistical difference between all the groups (Table 2). Bacterial loads were higher in the group of women with bacterial vaginosis, followed by intermediate and normal vaginal flora.

A PCA was performed to evaluate the distribution of normal flora, intermediate flora and bacterial vaginosis samples according to the parameters measured. As observed in Fig. 1, samples were distributed in two groups, the one on the left side shows a predominance of the intermediate and normal vaginal flora, while the other is predominately constituted by bacterial vaginosis samples. It can be noticed a clear overlap of normal and intermediate samples in the left side of the figure. 
Table 2

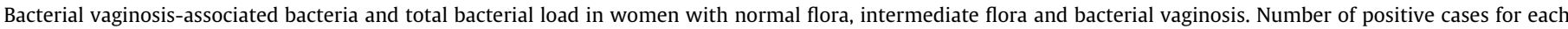
species $(\mathrm{N})$ and median bacterial load (number of copies/mL) in the vaginal samples.

\begin{tabular}{|c|c|c|c|c|}
\hline Parameters ${ }^{*}$ & Normal & Intermediate & Bacterial vaginosis & $\mathrm{P}^{* *}$ \\
\hline IL-1beta (pg/mL) & $7.8(0.0-286.2)^{b}$ & $28.7(0.0-462.4)^{\mathrm{a}}$ & $56.0(0.0-1950.0)^{\mathrm{a}}$ & $<0.0001$ \\
\hline IL-1 ra (ng/mL) & $668.5(70.4-4185.0)^{b}$ & $1008.0(0.0-3727.0)^{\mathrm{a}, \mathrm{b}}$ & $935.6(775.4-8067.0)^{\mathrm{a}}$ & 0.02 \\
\hline IL-6 (pg/mL) & $0.0(0.0-195.6)^{\mathrm{a}}$ & $0.0(0.0-205.4)^{\mathrm{a}}$ & $0.0(0.0-324.4)^{\mathrm{a}}$ & 0.66 \\
\hline $\mathrm{IL}-8(\mathrm{pg} / \mathrm{mL})$ & $294.3(0.0-2010.0)^{\mathrm{ab}}$ & $441.5(0.0-2053.0)^{\mathrm{a}}$ & $260.9(0.0-2220.0)^{\mathrm{b}}$ & 0.01 \\
\hline $\mathrm{IL}-10(\mathrm{pg} / \mathrm{mL})$ & $0.0(0.0-508.2)^{\mathrm{a}}$ & $36.7(0.0-417.1)^{\mathrm{a}}$ & $0.0(0.0-62.3)^{b}$ & $<0.0001$ \\
\hline TNF-alpha (pg/mL) & $0.0(0.0-80.1)^{a}$ & $0.0(0.0-1489.0)^{\mathrm{a}}$ & $0.0(0.0-657.9)^{\mathrm{a}}$ & 0.67 \\
\hline Sialidase $(\mathrm{ng} / \mathrm{mL})$ & $0.0(0.0-5.2)^{\mathrm{b}}$ & $0.0(0.0-0.04)^{\mathrm{b}}$ & $4.6(0.0-576.4)^{\mathrm{a}}$ & $<0.0001$ \\
\hline $16 \mathrm{~S}$ rRNA ( $\mathrm{nr}$ of copies/mL) & $10^{9}\left[10^{3}-10^{7}\right]^{\mathrm{c}}$ & $10^{8}\left[10^{5}-10^{9}\right]^{\mathrm{b}}$ & $10^{10}\left[10^{8}-10^{11}\right]^{\mathrm{a}}$ & $<0.0001$ \\
\hline Gardnerella vaginalis ( $\mathrm{nr}$ of copies/mL) & $0\left[0-10^{7}\right]^{\mathrm{c}}$ & $10^{2}\left[0-10^{6}\right]^{\mathrm{b}}$ & $10^{6}\left[0-10^{8}\right]^{a}$ & $<0.0001$ \\
\hline
\end{tabular}

* Values followed by the same letter did not differ statistically.

Kruskal Wallis test; Dunn's multiple comparison test; $\mathrm{P}<0.05$

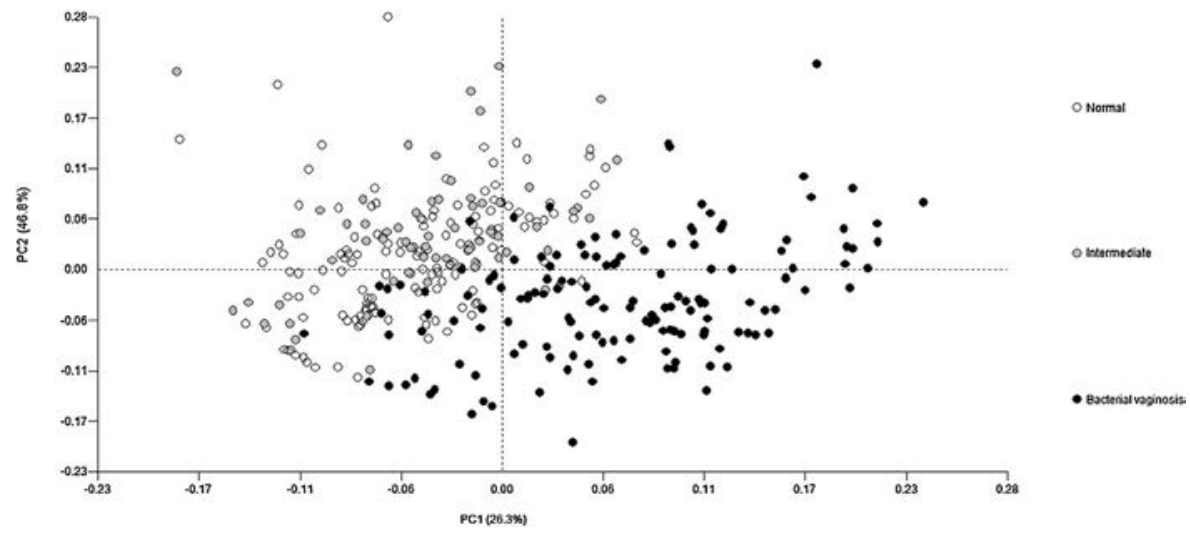


presented on the ordinate and abscissa axes represent the largest amount of variation in the data set.

\section{Discussion}

This study is the first full description of the cervicovaginal profile of cytokines and bacterial sialidases levels, as well as the $G$. vaginalis and total bacterial load according to the pattern of vaginal flora, based on the most widely accepted method for flora classification proposed by Nugent at al., in normal, intermediate flora and bacterial vaginosis (Nugent et al., 1991). The inclusion criteria of women in this study were very strict to assure that none of the samples had any concurrent infection that could interfere in the immunological and bacterial parameters measured. The analyses of the sociodemographic characteristics in the current study showed that some of the variables commonly associated with bacterial vaginosis, such as age and ethnicity, were not associated with the type of vaginal flora (Koumans et al., 2007; Ness et al., 2003). This inconstancy in the findings might be explained by the fact that we only included women in reproductive age and that Brazilian population is particularly composed by admixed ethnicities (Manta et al., 2013).

On the other hand, the present data are in agreement with the literature, as women who reported being single at time of enrollment, had smoking habit and with at least one previous episode of bacterial vaginosis were more likely to present bacterial vaginosis (Smart et al., 2004; Jones et al., 2007; Guédou et al., 2013). We are aware that smoking status can influence vaginal cytokine levels and this might have produced some biased results in the current study (Beigi et al., 2007). As expected, bacterial vaginosis women had significant higher vaginal $\mathrm{pH}$ and were more likely to have positive $\mathrm{KOH}$ test, both well-recognized markers of bacterial vaginosis (Amsel et al., 1983). Although women with intermediate flora also had significantly increased $\mathrm{pH}$ and positivity at $\mathrm{KOH}$ test, clinical diagnosis of this condition using these parameters and symptomatology is not sufficiently accurate (Gondo et al., 2011).

In agreement with the literature, the cervicovaginal levels of IL-1beta in both, intermediate flora and bacterial vaginosis, were increased in relation to normal vaginal flora (Basso et al., 2005; Cauci et al., 2003b; Marconi et al., 2013a,b,). As increased cervicovaginal levels of IL-1beta were already associated with pregnancy complications, such as abortion and premature birth (MattsyBaltzer et al., 1998), and also with increased risk for STI acquisition (Sturm-Ramirez et al., 2000), it can be hypothesized that women with bacterial vaginosis and intermediate flora are at same risk for the deleterious effects of high levels of IL-1beta. Regarding the IL-6 levels measured in this population, no difference could be observed among the groups. Although, as recently described by Donders et al. (2002), IL-6 levels may be elevated in aerobic vaginitis, several studies have failed in demonstrating IL-6 production induced by bacterial vaginosis (Hedges et al., 2006; Marconi et al., 2013b; Weissenbacher et al., 2010). Reinforcing these findings, Nikolaitchouk et al. (2008) did not find correlation between the number of bacterial vaginosis-associated bacteria with IL-6 levels. However, recent study that used a more sensitive method for cytokine quantification in vaginal samples showed that IL-6 is actually increased in bacterial vaginosis (Spear et al., 2011). We might have failed in showing this difference, as the commercial assay used was only able to detect presence of IL- 6 in $34 \%$ of the samples (data not shown).

Still in relation to the inflammatory response, the pattern of cervicovaginal levels of IL-8 is controversial. Some studies have shown this chemokine is significantly increased in bacterial vaginosis (Hedges et al., 2006; Marconi et al., 2014), while other authors have failed in demonstrating such association (Cauci et al., 2003b; Marconi et al., 2013a,b). Actually, IL-8 is a potent neutrophil 
chemotactic factor and, as bacterial vaginosis is not associated with increases in neutrophil counts, IL-8 levels are expected to be unchanged in this condition (Cauci et al., 2002b). Hereby we were able to show that intermediate flora is associated with increased IL8 when compared to bacterial vaginosis, but unchanged in relation to normal flora. This finding suggests that, in fact, IL-8 may present some differences in the bacterial composition in relation to normal and bacterial vaginosis flora. Supporting this evidence, it was already demonstrated that the quantity of the different bacterial species found in vaginal flora correlates differently with local levels of IL-8 (Nikolaitchouk et al., 2008). Additionally, it was recently demonstrated by our group that aerobic vaginitis, an entity that also differs from bacterial vaginosis in terms of bacterial composition, increases the local levels of IL-8 (Marconi et al., 2013b). Although it was known that IL-8 levels correlate negatively with quantity of lactobacilli (Spear et al., 2008), it is still not well established the exact deleterious effects of increased vaginal IL-8 levels. However, it was recently shown that in HIV-positive women, vaginal IL-8 levels correlate positively with HIV RNA concentrations (Mitchell et al., 2011), providing evidence that women with intermediate flora may present increased HIV shedding and potentially increased risk of transmission.

The proinflammatory cytokine TNF-alpha is normally found in low and unchanged levels in the lower genital tract from women with normal and altered vaginal flora (Marconi et al., 2013a,b; Mattsy-Baltzer et al., 1998), as supported by the current study that showed same TNF-alpha levels also in intermediate flora. On the other hand, there are few data available regarding the cervicovaginal levels of the anti-inflammatory cytokine IL-10 and they show no difference between bacterial vaginosis and normal flora (Weissenbacher et al., 2010). This study is consistent with this observation that indeed normal and bacterial vaginosis groups have same IL-10 levels, but it also shows that women with intermediate flora have increased IL-10. It is well established that bacterial lipopolysaccharide induces an initial burst of proinflammatory cytokine and release by several inflammatory cells. This event is followed by increased IL-10 production for down-regulating the inflammatory response. Therefore, the high IL-10 level in intermediate flora points out an amplified inflammatory response found in this type of flora, differently to what is observed in bacterial vaginosis, condition well-known by the absence of inflammatory cell infiltrate (Cauci et al., 2003b). When evaluating IL-1 ra, another antiinflammatory cytokine, it was observed increases only in women with bacterial vaginosis when compared to those with normal flora. The role of IL-1ra is to modulate the proinflammatory activity of IL1 beta and, in agreement with the current findings, it was already demonstrated that cervicovaginal loads of $G$. vaginalis correlates with local levels of this cytokine (Genc et al., 2004).

Regarding the microbial composition of the vaginal flora, it was already demonstrated that bacterial vaginosis is associated with increase in bacterial diversity and quantity (Nikolaitchouk et al., 2008; Ravel et al., 2011; Spiegel et al., 1980). Corroborating with this previous knowledge, it is hereby demonstrated that total bacterial load is different among all flora types, pointing out that intermediate flora has increased bacterial load when compared to women with normal flora. Similar results were found in relation to the sialidase-producer species, G. vaginalis. Despite women with intermediate flora show higher loads of G. vaginalis when compared to normal flora, no difference in sialidases levels were observed between this two flora types. It was demonstrated by Cauci et al. (2002a) that intermediate flora has increased sialidase levels in relation to normal flora, which differs from our study. This discrepancy in the findings might be due to the fact that these authors evaluated only pregnant women, while it was recently demonstrated that pregnant women present increased instability of vaginal microbiota when compared to nonpregnants (Romero et al., 2014). In fact, the finding of increased sialidase levels in bacterial vaginosis is supported by other studies (Cauci et al., 2002b; Marconi et al., 2013a) and reinforces the immunologic impairment that may be present in the lower genital tract of women with this condition (Lewis et al., 2012).

The microbiological and immunological parameters were combined for an evaluation using PCA and showed that the general patterns of normal and intermediate flora are similar, while samples from women with bacterial vaginosis tend to form a distinct group. However, our data provide evidence that intermediate flora should not be overlooked, as it is associated with changes in specific parameters the vaginal milieu, which could bring adverse consequences for women's reproductive health. Moreover, Nugent category of intermediate flora fails to identify those women at increased risk for these deleterious effects associated to these parameters, as PCA analysis shows no difference between this condition and normal flora (Cherpes et al., 2003; Mitchell et al., 2011; Sturm-Ramirez et al., 2000).

Considering that recent studies have been consistent in demonstrating that vaginal flora is highly dynamic over time (Lambert et al., 2013; Ravel et al., 2013), further longitudinal studies should be conducted to evaluate the hypothesis that intermediate flora do not bring any serious consequences when detected, whereas this scenario changes if this condition persists for longer periods of time. In this case, such women would be at risk for the severe consequences already associated with this type of flora.

\section{Acknowledgement}

We thank the support by Fundação de Amparo a Pesquisa do Estado de São Paulo-FAPESP (Grant: 2009/50560-7).

\section{References}

Amsel, R., Totten, P.A., Spiegel, C.A., Chen, K.C.S., Eschenbach, D.A., Holmes, K.K., 1983. Nonspecific vaginitis: diagnostic criteria and microbial and epidemiologic associations. Am. J. Med. 74, 14-22.

Basso, B., Giménez, F., López, C., 2005. IL-1beta, IL-6 and IL-8 levels in gyneco-obstetric infections. Infect. Dis. Obstet. Gynecol. 13, 207-211.

Beigi, R.H., Yudin, M.H., Cosentino, L., 2007. Cytokines, pregnancy, and bacterial vaginosis: comparison of levels of cervical cytokines in pregnant and nonpregnant women with bacterial vaginosis. J. Infect. Dis. 196, 1355-1560.

Brotman, R.M., Bradford, L.L., Conrad, M., et al., 2012. Association between Trichomonas vaginalis and vaginal bacterial community composition among reproductive-age women. Sex. Transm. Dis. 39, 807-812

Cauci, S., Guaschino, S., Driussi, S., et al., 2002a. Correlation of local interleukin-8 with immunoglobulin A against Gardnerella vaginalis hemolysin and with prolidase and sialidase levels in women with bacterial vaginosis. J. Infect. Dis. 185, 1614-1620.

Cauci, S., Hitti, J., Noonan, C., et al., 2002b. Vaginal hydrolytic enzymes, immunoglobulin A against Gardnerella vaginalis toxin, and risk of early preterm birth among women in preterm labor with bacterial vaginosis or intermediate flora. Am. J. Obstet. Gynecol. 187, 877-881.

Cauci, S., Thorsen, P., Schendel, D.E., et al., 2003a. Determination of immunoglobulin A against Gardnerella vaginalis hemolysin, sialidase, and prolidase activities in vaginal fluid: implications for adverse pregnancy outcomes. J. Clin. Microbiol. 41, 435-438.

Cauci, S., Guaschino, S., De Aloysio, D., et al., 2003b. Interrelationships of interleukin-8 with interlukin-1b and neutrophils in vaginal fluid of healthy ad bacterial vaginosis positive women. Mol. Hum. Reprod. 9, 53-58.

Cherpes, T.L., Meyn, L.A., Krohn, M.A., et al., 2003. Association with acquisition of herpes simplex virus type 2 in women with bacterial vaginosis. Clin. Infec. Dis. 37, 319-325.

Donders, G.G., Vereecken, A., Bosmans, E., et al., 2002. Definition of a type of abnormal vaginal flora that is distinct from bacterial vaginosis: aerobic vaginitis. BJOG 109, 34-43.

Donders, G.G., 2007. Definition and classification of abnormal vaginal flora. Best Pract. Res. Clin. Obstet. Gynecol. 21, 355-373.

Genc, M.R., Witkin, S.S., Delaney, M.L., et al., 2004. A disproportionate increase in IL-1 over IL-1ra in the cervicovaginal secretions of pregnant women with altered vaginal microflora correlates with preterm birth. Am. J. Obstet. Gynecol. 190, 1191-1197.

Gondo, F., da Silva, M.G., Polettini, J., et al., 2011. Vaginal flora alterations and clinical symptoms in low-risk pregnant women. Gynecol. Obstet. Invest. 71, $158-162$. 
Guédou, F.A., Damme, L.V., Mirembe, F., et al., 2012. Intermediate vaginal flora is associated with HIV prevalence as strongly as bacterial vaginosis in a cross-sectional study of participants screened for a randomised controlled trial. Sex. Transm. Infect. 88, 545-551.

Guédou, F.A., Van Damme, L., Deese, J., et al., 2013. Behavioural and medical predictors of bacterial vaginosis recurrence among female sex workers: longitudinal analysis from a randomized controlled trial. BMC. Infect. Dis. 13, 208.

Guédou, F.A., Damme, L.V., Deese, J., et al., 2014. Intermediate vaginal flora and bacterial vaginosis are associated with the same factors: findings from an exploratory analysis among female sex workers in Africa and India. Sex. Transm. Infect. 90, 161-164.

Hedges, S.R., Barrientes, F., Desmond, R.A., et al., 2006. Local and systemic cytokine levels in relation to changes in vaginal flora. J. Infect. Dis. 193, 556-562.

Ho, B.S., Feng, W.G., Wong, B.K., et al., 1992. Polymerase chain reaction for the detection of Neisseria gonorrhoeae in clinical samples. J. Clin. Pathol. 45, 439-442.

Jones, F.R., Miller, G., Gadea, N., et al., 2007. Prevalence of bacterial vaginosis among young women in low-income populations of coastal Peru. Int. J. STD AIDS 18, 188-192.

Klebanoff, M.A., Schwebcke, J.R., Zhang, J., et al., 2004. Vulvovaginal symptoms in women with bacterial vaginosis. Obstet. Gynecol. 104, 267-272.

Koumans, E.H., Stemberg, M., Bruce, C., et al., 2007. The prevalence of bacterial vaginosis in the United states, 2001-2004; associations with symptoms, sexual behaviors, and reproductive health. Sex. Transm. Dis. 34, 864-869.

Lambert, J.A., John, S., Sobel, J.D., et al., 2013. Longitudinal analysis of vaginal microbiome dynamics in women with recurrent bacterial vaginosis: recognition of the conversion process. PLoS One 8, e82599.

Lewis, W.G., Robinson, L.S., Perry, J., et al., 2012. Hydrolysis of the secreted sialoglycoprotein Immunoglobulin A (IgA) in ex vivo and biochemical models of bacterial vaginosis. J. Biol. Chem. 287, 2079-2089.

Manta, F.S.N., Pereira, R., Vianna, R., et al., 2013. Revisiting the genetic ancestry of Brazilians using autosomal AIM-Indels. PLoS One, $8 \mathrm{e} 75145$.

Marconi, C., Donders, G.G., Martin, L.F., et al., 2012. Chlamydial infection in a high risk population: association with vaginal flora patterns. Arch. Gynecol. Obstet. $285,1013-1018$

Marconi, C., Donders, G.G., Parada, C.M.G.L., et al., 2013a. Do Atopobium vaginae, Megasphaera sp. and Leptotrichia sp. change the local innate immune response and sialidase activity in bacterial vaginosis? Sex. Transm. Infect. 89, 167-173.

Marconi, C., Donders, G.G., Bellen, G., et al., 2013b. Sialidase activity in aerobic vaginitis is equal to levels during bacterial vaginosis. Eur. J. Obstet. Gynecol. Reprod. Biol. 167, 205-209.

Marconi, C., Santos-Greatti, M.M., Parada, C.M., et al., 2014. Cervicovaginal levels of proinflammatory cytokines are increased during chlamydial infection in bacterial vaginosis but not in lactobacilli-dominated flora. J. Low. Genit. Tract. Dis. 18, 261-265

Martin, H.L., Richardson, B.A., Nyange, P.M., et al., 1999. Vaginal lactobacilli, microbial flora, and risk of human immunodeficiency virus type 1 and sexually transmitted disease acquisition. J. Infect. Dis. 180, 1863-1868.

Mattsy-Baltzer, I., Platz-Christensen, J.J., Hosseini, N., et al., 1998. IL-1beta, IL-6, TNF alpha, fetal fibronectin, and endotoxin in lower genital tract of pregnant women with bacterial vaginosis. Acta Obstet. Gynecol. Scand. 77, 701-706.

Mitchell, C., Hitti, J., Paul, K., et al., 2011. Cervicovaginal shedding of HIV type 1 is related to genital tract inflammation independent of changes in vaginal microbiota. AIDS. Res. Hum. Retroviruses 27, 35-39.
Ness, R.B., Hillier, S., Richter, H.E., et al., 2003. Can known risk factors explain racial differences in the occurrence of bacterial vaginosis? J. Natl. Med. Assoc. 95, 201-212.

Nikolaitchouk, N., Andersch, B., Falsen, E., et al., 2008. The lower genital tract microbiota in relation to cytokine, SLPI and endotoxin levels: application of checkerboard DNA-DNA hybridization (CDH). APMIS 116, 263-277.

Nugent, R.P., Krohn, M.A., Hillier, S.L., 1991. Reliability of diagnosing bacterial vaginosis is improved by a standardized method of Gram stain interpretation. J. Clin. Microbiol. 29, 297-301.

Ravel, J., Gajer, P., Abdo, Z., et al., 2011. Vaginal microbiome of reproductive-age women. Proc. Natl. Acad. Sci. U. S. A. 108, 4680-4687.

Romero, R., Hassan, S.S., Gajer, P., et al., 2014. The composition and stability of the vaginal microbiota of normal pregnant women is different from that of non-pregnant women. Microbiome 2, 4.

Santiago, G.L., Deschaght, P., El Aila, N., et al., 2011. Gardnerella vaginalis comprises three distinct genotypes of which only two produce sialidase. Am. J. Obstet. Gynecol. 204, e1-7.

Schwebke, J.R., 2001. Role of vaginal flora as a barrier to HIV acquisition. Curr. Infect. Dis. Rep. 3, 152-155.

Sewankambo, N., Gray, R.H., Wawer, M.J., et al., 1997. HIV-1 infection associated with abnormal vaginal flora morphology and bacterial vagnosis. Lancet 350, $546-550$

Smart, S., Singal, A., Mindel, A., 2004. Social and sexual risk factors for bacterial vaginosis. Sex. Transm. Infect. 80, 58-62.

Smits, T.H., Devenoges, C., Szynalski, K., et al., 2004. Development of a real-time PCR method for quantification of the three genera Dehalobacter, Dehalococcoides, and Desulfitobacterium in microbial communities. J. Microbiol. Methods 57, 369-378.

Sobel, J.D., 2000. Bacterial vaginosis. Annu. Rev. Med. 51, 349-356.

Spear, G.T., Zariffard, M.R., Cohen, M.H., et al., 2008. Vaginal IL-8 levels are positively associated with Candida albicans and inversely with lactobacilli in HIV-infected women. J. Reprod. Immunol. 78, 76-79.

Spear, G.T., Kendrick, S.R., Chen, H.Y., 2011. Multiplex immunoassay of lower genital tract mucosal fluid from women attending an urban STD clinic shows broadly increased IL1 beta and lactoferrin. PLoS One 6, e19560.

Spiegel, C.A., Amsel, R., Eschenbach, D., et al., 1980. Anaerobic bacteria in nonspecific vaginitis. N. Engl. J. Med. 303, 601-617.

Srinivasan, S., Liu, C., Mitchell, C.M., et al., 2010. Temporal variability of human vaginal bacteria and relationship with bacterial vaginosis. PLoS One 5, e10197.

Sturm-Ramirez, K., Gaye-Diallo, A., Eisen, G., et al., 2000. High levels of tumor necrosis factor-alpha and interleukin-1 beta in bacterial vaginosis may increase susceptibility to human immunodeficiency virus. J. Infect. Dis. 182, 467-473.

Weiesenfeld, H.C., Hillier, S.L., Krohn, M.A., et al., 2003. Bacterial vaginosis is strong predictor of Neisseria gonorrhoeae and Chlamydia trachomatis infection. Clin. Infect. Dis. 36, 663-668.

Weissenbacher, T., Walter, C., Mylonas, I., et al., 2010. Interleukin-6, interleukin-10 and interleukin-12 in vaginal fluid from women with bacterial vaginosis. Arch. Gynecol. Obstet. 281, 77-80.

Zariffard, M.R., Saifuddin, M., Sha, B.E., et al., 2002. Detection of bacterial vaginosis-related organisms by real-time PCR for lactobacilli, Gardnerell vaginalis and Mycoplasma hominis. FEMS. Immunol. Med. Microbiol. 34, 277-281.

Ravel, J., Brotman, R.M., Gajer, P., et al., 2013. Daily temporal dynamics of vagina microbiota before, during, and after episodes of bacterial vaginosis. Microbiome 1, 29 